Amanda Roberts ORCID iD: 0000-0002-0153-0316

\title{
Reoperation cascade in postmastectomy breast reconstruction and its associated factors: Results from a long-term population-based study
}

\section{Authors:}

Amanda Roberts MD, MPH, Division of General Surgery, Sunnybrook Health

Sciences Centre, Toronto, Ontario, Canada

Nancy N. Baxter MD, PhD, Department of Surgery, Li Ka Shing Knowledge

Institute, St. Michael’s Hospital, Institute of Health Policy, Management, and

Evaluation, Dalla Lana School of Public Health, University of Toronto, Institute for

Clinical Evaluative Sciences, Toronto, Ontario, Canada

Rinku Sutradhar PhD, Institute for Clinical Evaluative Sciences, Toronto, Ontario,

Canada, Institute of Health Policy, Management, and Evaluation, Dalla Lana School

of Public Health, University of Toronto, Institute for Clinical Evaluative Sciences, Toronto, Ontario, Canada

Cindy Lau MPH, Institute for Clinical Evaluative Sciences, Toronto, Ontario, Canada

Toni Zhong MD, MHS, Division of Plastic and Reconstructive Surgery, University

Health Network, Toronto, Ontario, Canada

This is the author manuscript accepted for publication and undergone full peer review but has not been through the copyediting, typesetting, pagination and proofreading process, which may lead to differences between this version and the Version of Record. Please cite this article as doi: 10.1002/jso.26166.

This article is protected by copyright. All rights reserved. 
Corresponding Author:

Amanda Roberts MD MPH

Sunnybrook Health Science Centre

T2-063, 2075 Bayview Ave

Toronto, Ontario M4N 3M5

phone: 416-4800-5000 fax: 416-480-6002

amanda.roberts@sunnybrook.ca

Running Head: Breast Reconstruction Reoperations

\section{Synopsis:}

A population-based retrospective cohort study examining factors that influence unplanned reoperations after postmastectomy breast reconstruction (PMBR). Procedure and treatment related factors impact reoperations, and each additional procedure increases the likelihood of more unplanned reoperations resulting in a "reoperation cascade".

Data Availability Statement: Research data are not shared.

\section{Abstract \\ Background:}

This article is protected by copyright. All rights reserved. 
Unplanned surgeries following postmastectomy breast reconstruction (PMBR) may be required to treat complications or to revise the reconstructed breast. The primary objective of this study was to examine factors that influenced unplanned reoperations after PMBR.

\section{Methods:}

A retrospective cohort study using provincial databases in Ontario, Canada was completed. Patients with breast cancer underwent mastectomy between April 2002 and March 2012 followed by immediate or delayed PMBR. Primary outcome was time from PMBR to unplanned reoperations measured in years. The Anderson-Gill counting process model was used to estimate the risk of recurrent unplanned reoperations over time. Univariate and multivariate analyses were completed to examine the association between covariates.

\section{Results:}

3,066 women underwent PMBR and 51.7\% had at least one unplanned reoperation. Unplanned breast reoperation was significantly associated with microsurgical tissue versus implant-based reconstruction (HR1.27), radiation after PMBR (HR 1.22), surgery at a non-teaching hospital (HR 1.16), patient comorbidity score (HR 1.02), and prior unplanned reoperations (HR 1.25).

\section{Conclusions:}

Our study provides important long-term population-level data regarding factors influencing unplanned reoperations after PMBR. Patients undergoing microsurgical This article is protected by copyright. All rights reserved. 
PMBR or postmastectomy radiation had a higher rate of additional procedures. Every additional reoperation also increases the likelihood of unplanned reoperations resulting in a "reoperation cascade".

Key words: Breast Cancer, Mastectomy, Reconstruction, Reoperations

\section{Introduction}

High quality healthcare delivers optimized outcomes to patients while minimizing unnecessary utilization and costs for the healthcare system. Unplanned reoperations are a surgical quality indicator for many types of surgeries [1, 2], but they have not been specifically examined as a quality indicator for post-mastectomy breast reconstruction (PMBR). Rates of PMBR are increasing [3] and additional surgeries to treat complications or revise the breast mound can cause morbidity and dissatisfaction to the patient [4], in addition to unnecessary healthcare utilization and increased costs $[5,6]$.

The literature lacks a long-term evaluation of unplanned reoperations on a population-based level following PMBR [6-8]. Large population databases and registries that evaluate outcomes, such as the National Surgical Quality Improvement Program (NSQIP) and Surveillance, Epidemiology and End Results program (SEER) are not adequate to provide long-term reoperation rates. Data from NSQIP are limited to the first 30 days after surgery and SEER does not collect complication or reoperation outcomes. Our previous analysis using Ontario population-based data showed that the majority (84.3\%) of PMBR reoperations occur greater than 30-days post-operatively, and $44 \%$ of PMBR patients had at least one unplanned reoperation This article is protected by copyright. All rights reserved. 
over a mean follow up of 5 years [9]. Unplanned reoperations may lead to additional interventions, surgery or hospitalizations - a possible "cascade" of care. Since these unplanned reoperations are an important quality indicator of PMBR from both the perspective of the patient as well as the healthcare system, the objective of this study was to examine the factors that influence long-term unplanned reoperations after PMBR in breast cancer patients using a population-based registry.

\section{Materials and Methods}

We conducted a population-based retrospective cohort study using provincial administrative databases in Ontario, Canada. Our cohort included women between the ages of 18-65 years who underwent a therapeutic mastectomy for invasive breast cancer between April 1, 2002 and March 31, 2012 followed by an immediate or delayed PMBR. Patients were followed from the date of their PMBR surgery to March 31 2013, or death. We obtained research ethics approval from the University Health Network and Sunnybrook Health Sciences Centre (Toronto, Ontario, Canada).

We accessed our data sources through the ICES and linked by patient-specific encrypted identifiers. Data sources included: (1) Canadian Institute for Health Information - Discharge Abstract Database and National Ambulatory Care Reporting System (CIHI-DAD and CIHI-NACRS): contains details on all in-hospital and outpatient discharges since 1988 and 2002 respectively (2) Ontario Registered Persons Database (RPDB): provides demographic information on anyone who has received a health card in Ontario, covering nearly everyone in the province (3) Ontario Health Insurance Plan (OHIP): provides details on medical services billed by

This article is protected by copyright. All rights reserved. 
Ontario physicians through a publicly funded universal health insurance plan (4) ICES Physician Data Base (IPDB): contains annual demographics, specialization and workload of Ontario physicians (5) Institution Information System (INST): contains information about Ontario health care institutions funded by the Ministry of Health and Long-Term Care (MOHLTC) (6) Ontario Cancer Registry: includes information for all incident breast cancers diagnosed in Ontario and (7) Ontario Diabetes Database: identifies patients with physician-diagnosed diabetes mellitus in Ontario.

\section{Identification of PMBR cohort:}

An established patient cohort of women between 18 and 65 years of age, residing in Ontario, who underwent mastectomy between April 1, 2002 and March 31, 2012 was previously identified from the CIHI-DAD/NACRS data source [10]. Patients up to age 65 years were included in this established patient cohort as immediate and delayed PMBR were performed most commonly in this age category during the time period of our study. Breast reconstructions were identified using International Classification of Diseases, $10^{\text {th }}$ edition (ICD-10) and OHIP billing codes. Immediate breast reconstruction (IBR) and delayed breast reconstruction (DBR) were defined as breast mound reconstruction performed during the same surgery as mastectomy or within 3 years of mastectomy procedure date respectively. Patients who underwent delayed PMBR had their primary mastectomy procedure date between 2002 and 2008, allowing for DBRs until 2011 to be included.

\section{Definition and Identification of Unplanned Reoperations:}

Unplanned procedures included operations to treat 1) acute surgical complications This article is protected by copyright. All rights reserved. 
such as hematoma or abscess, or vascular reoperation in a microsurgical PMBR; 2) subacute or long-term complications to the breast mound such as capsular contraction correction, implant removal, scar revision, debridement and skin graft, or a second reconstruction for a failed primary reconstruction; and 3) long term complications at the donor site such as abdominal bulge/hernia repair following previous transverse rectus abdominis myocutaneous (TRAM) or deep inferior epigastric perforator (DIEP) flap. Nipple areolar complex (NAC) reconstruction, contralateral balancing procedure such as breast reduction or augmentation or mastopexy $+/$ - augmentation to the native breast, and one surgery for breast mound revision at the same time as breast balancing were considered expected procedures following the primary PMBR. These surgeries were considered a planned reoperation. For implant-based reconstruction, an expander to implant exchange was defined as a planned procedure. Any additional revision or correction to the reconstructed breast mound before or after the expander to implant exchange was considered unplanned. Any additional capsulectomy or capsulotomy procedure other than at the time of the tissue expander exchange surgery was also considered unplanned. Re-attempts of greater than one balancing procedure (for unilateral PMBR) was considered an unplanned reoperation for our study.

Reoperations following PMBR were identified through OHIP billing codes submitted by general or plastic surgeons.

Identification of Covariates

Patient Characteristics

This article is protected by copyright. All rights reserved. 
Patient age at PMBR was determined through linkage with the RPDB. The Johns Hopkins ACG ${ }^{\circledR}$ system (version 10 ) was used to create a co-morbidity score for each patient based on diagnosis codes within the two years prior to PMBR date.

Procedure details

Laterality: Unilateral versus bilateral PMBR was determined based on OHIP mastectomy codes. PMBR Method and Timing: IBR occurred at the time of primary (or first) mastectomy. DBR occurred months to years (up to 3 years) after the primary mastectomy. The method of PMBR was determined based on OHIP procedure codes. Categories of PMBR were: implant-based, microsurgical tissue (i.e. free TRAM or DIEP), and pedicled tissue (i.e. pedicled TRAM, latissimus dorsi flap). Pedicledtissue reconstruction with an implant code was classified within the pedicled category.

Cancer and Treatment details

Indication for Mastectomy: A diagnosis of invasive breast cancer was determined through linkage with the Ontario Cancer Registry (OCR). Chemotherapy: Receipt of chemotherapy within 12 months (before or after) of PMBR was determined through identification of OHIP chemotherapy codes. Radiation: Radiation planning codes were used as a proxy measure for radiation delivery. Patients who underwent radiation were identified using radiation planning codes within the 12 months following a breast cancer diagnosis (OCR).

Physician Characteristics

This article is protected by copyright. All rights reserved. 
Gender and years in practice: Plastic surgeon gender and years in practice were determined from the IPDB. Volume: The average volume of breast reconstructions per year was determined based on OHIP billings for each plastic surgeon for two years prior to PMBR date.

Institutional characteristics

Designation: Teaching hospital status was determined from the INST. Volume: The average volume of PMBR procedures per year per institution was determined for two years prior to the PMBR date for each patient.

\section{Analysis:}

The outcome was time from PMBR to unplanned reoperations among invasive breast cancer patients measured in years. Starting from PMBR, the repeated events of unplanned reoperations were measured in continuous time until censoring (end of follow-up or death). The Andersen-Gill counting process (AG-CP) model was used to estimate the rate of recurrent unplanned reoperations over time [11,12]. Univariate and multivariate analyses using the AG-CP model were implemented to examine the association between covariates and the rate of unplanned reoperations. Chemotherapy and radiation were incorporated as a time-varying covariate while all other covariates were included as baseline measures. Multicollinearity between variables was evaluated using a variance inflation factor cut-off of 2.5. Separate analyses were completed for patients with invasive breast cancer who had unplanned breast reoperations. Variables that were hypothesized to have significant interactions were tested in the model including chemotherapy and the timing of the breast This article is protected by copyright. All rights reserved. 
reconstruction procedure (immediate versus delayed) and radiation and procedure type (implant, pedicled, microsurgical). A p-value of $<0.05$ was considered statistically significant. SAS version 9.4 statistical software (SAS Institute, Cary, NC) was used to perform all analyses. Research data are not shared.

\section{Results}

Between April 12002 and March 31 2012, a total of 3,066 women with invasive breast cancer underwent a therapeutic mastectomy followed by PMBR (either immediate or delayed) in the province of Ontario. The majority of patients (59.1\%) underwent reconstruction using an implant-based technique. The remainder of patients underwent either a pedicled or microsurgical tissue-based reconstruction, with microsurgical techniques increasing, and pedicled techniques decreasing, over the time course of our study. A total of 1,584 women (51.7\%) had at least one unplanned reoperation on their breast or donor site (Table 1). Of patients who underwent at least one unplanned reoperation, 814 (51.4\%) had only one unplanned reoperation, 348 (22.0\%) had two unplanned reoperations and 422 (26.6\%) had three or more unplanned reoperations. The most common type of reoperation included "breast mound revision” across all types of reconstruction. Patients with unplanned reoperations had significantly higher comorbidity scores (9.44 vs 8.95, $\mathrm{p}<0.001$ ), and had a higher proportion of microsurgical tissue reconstruction compared to the patients with no unplanned reoperations ( $22.9 \%$ vs $16.2 \%, \mathrm{p}<0.001)$ (Table 1$)$. Of note, unplanned reoperations during the first year after immediate microsurgical PMBR were over 50\% during 2002 and 2003 and decreased to 12.5\% by 2012. We also found that patients who had at least one unplanned reoperation more frequently This article is protected by copyright. All rights reserved. 
had their PMBR in a nonteaching hospital ( $48.1 \%$ vs $38.9 \%, \mathrm{p}<0.001)$, and were more frequently reconstructed by plastic surgeons with a lower breast reconstruction volume (31.7 vs 37.9 PMBRs per year, $\mathrm{p}<0.001$ ) and fewer years in practice (10.8 vs 11.5 years, $\mathrm{p}=0.007)$ compared to their counterparts.

To isolate factors associated specifically with breast reoperations, the risk of unplanned reoperations in the breast only was evaluated (Table 2). When evaluating PMBR reoperations, specific influencing factors (such as radiation) only impact reoperations on the breast and not the other donor sites - therefore, we chose to focus only on breast reoperations to allow for a more accurate evaluation of treatment factors influencing PMBR reoperations. A total of 1,472 women (48.0\%) had at least one unplanned breast mound reoperation. A significant increased hazard of unplanned breast reoperation was associated with microsurgical tissue PMBR compared to implant based PMBR (HR1.27, 95\% CI: 1.12 - 1.45), radiation after PMBR (HR 1.22, 95\% CI: 1.09 - 1.37), surgery at a non - teaching hospital (HR 1.16, 95\% CI: $1.03-1.30$ ), patient comorbidity score (HR 1.02, 95\% CI: $1.00-1.03$ ) and prior unplanned reoperations in the same patient (HR 1.25, 95\% CI: $1.18-1.33$ ) (Table 2). The timing of reconstruction relative to mastectomy (immediate vs. delayed) did not impact the risk of unplanned reoperation (HR 1.04, $\mathrm{p}=0.47)$ To further evaluate the impact of specific factors on reoperations for patients undergoing immediate reconstruction, the risk of unplanned reoperations for only patients undergoing immediate breast reconstruction was evaluated. The percentage of patients undergoing immediate reconstruction $(\mathrm{N}=1714)$ followed by radiation was 15.9\% (186/1173) for implant-based, 12.3\% (33/269) for pedicled-tissue and 9.9\% This article is protected by copyright. All rights reserved. 
(27/272) for microsurgical-tissue. We found a statistically significant increased risk of reoperations to the breast for patients receiving postmastectomy radiation compared to no radiation (HR 1.35, CI: 1.14 - 1.59). We examined this relationship in detail by stratifying into the three different types of PMBR methods, and we found that this increased risk was only significant for patients undergoing immediate implant-based reconstruction. The rate of unplanned reoperations significantly increased by $56 \%$ for implant patients who received radiation versus patients who did not (HR 1.56, CI: $1.32-1.84)$.

\section{Discussion}

Our study provides an inclusive, long-term, population-level overview of unplanned reoperations across all PMBR methods and timing. Unlike most studies evaluating reoperations, we have evaluated reoperations beyond the typical 30-day postoperative period, up to 10 years post-operatively. For breast cancer patients who undergo PMBR, close to half will require at least one additional unplanned reoperation during their first 10 years of follow-up. These unplanned reoperations are significantly associated with patient comorbidity score (HR 1.02), type of PMBR (microsurgical versus implant HR 1.27), postmastectomy radiation (HR1.22), surgery at a non-teaching hospital (HR 1.16), and having had a previous unplanned reoperation (HR 1.25).

We intentionally sought to study the effect of radiation in IBR. For breast cancer patients undergoing IBR (implant or microsurgical) followed by radiation, this risk of

unplanned reoperation was 35\%. For patients undergoing implant-based

This article is protected by copyright. All rights reserved. 
reconstruction, the risk of unplanned reoperation was $56 \%$ higher in those who received radiation to their implant reconstruction compared to patients who did not receive radiation. Patients who had either microsurgical tissue or pedicled tissue reconstruction tolerated radiation better and were not seen to have significantly increased rates of unplanned reoperations. Similarly, the literature has demonstrated an increased risk of reoperation after radiation for immediate implant-based PMBR but no difference for immediate autologous PMBR $[13,14]$. Radiation to an implantreconstructed breast can cause pathologic capsular contracture around the implant, decreased patient satisfaction, and increased rates of revisions for capsulectomy and higher reoperation in this group $[15,16]$.

We observed an increased risk of unplanned reoperation for microsurgical tissue reconstruction compared (HR 1.27) to implant-based reconstruction, even after controlling for radiation. Consistent with our findings, a multicenter study found the risk of major complications (reoperation or re-hospitalization) was highest for microsurgical PMBR reconstruction compared to implant based reconstruction (OR 1.75) over a one year follow up period [17]. Qin et al also found a higher rate of complications for tissue-based versus implant-based reconstruction citing wound issues as the most common issue for tissue reconstruction [18]. A possible contributing factor to the higher microsurgical reoperation rate in our study is that a significant portion of our primary PMBR procedures took place in the time period between 2002 to 2008 before refinements in microsurgery techniques made these procedures far safer and before a major shift from pedicled to microsurgical reconstruction occurred [19-21]. In our study, the rates of unplanned reoperation were

This article is protected by copyright. All rights reserved. 
over 50\% for patients who had immediate microsurgical PMBR during 2002 and 2003 but these rates dropped over time. The rate of unplanned reoperation during the first year after an immediate microsurgical PMBR completed in 2012 was only $12.5 \%$, which is more in line with contemporary studies [22]. It was also noted the pedicled tissue reconstruction had a lower risk of unplanned reoperation compared to implant-based reconstruction (HR 0.64, p <0.0001) which may be due to more familiarity with the procedure during this time period and the lack of microvascular anastomosis when compared to the free-flap DIEP reconstructions.

The most consistent factor influencing reoperation rate across timing and type of PMBR in our study was the receipt of a previous unplanned reoperation in the same patient (HR 1.25). A significant proportion of PMBR patients require at least one unplanned reoperation over long-term follow-up and approximately one quarter of these patients will have three or more reoperations [9]. Forster et al similarly found that $25 \%$ of patients who underwent breast augmentation underwent more than one reoperation over a 10-year follow up period, calling this a "reoperation cascade” [23]. This phenomenon is not documented in the PMBR literature - likely due to the short term follow up of most outcome evaluations. Our analysis indicates that patients who start with at least one unplanned reoperation have an increased risk for another unplanned reoperation - therefore by preventing these initial reoperations, we may be able to stop the subsequent cascade that may follow for a significant proportion of our PMBR patients. The long-term follow up is a key strength of our study. While reoperation within the immediate post-operative period is an important quality metric, we found $80 \%$ of unplanned reoperations occurred $>30$ days after the index PMBR This article is protected by copyright. All rights reserved. 
thus studies focusing only on the early post-operative period will exclude the majority of reoperations and fail to identify a "reoperation cascade".

The use of administrative data has inherent limitations. We were unable to identify specific patient factors such as BMI or smoking status, in-situ breast cancer diagnosis, breast/chest wall specific radiation, laterality of reoperations and the potential misclassification of procedure codes. The lack of ability to identify laterality may impact the assessment of bilateral surgery as a risk factor for unplanned reoperation as the rates of reoperation overall are high for unilateral surgery, therefore adding the second breast may not significantly change that overall risk. We were unable to determine if reoperations were completed on only one breast or two breasts in the cases of bilateral surgery due to the limitations of our administrative data. This information would be helpful to determine if both breasts have a higher risk of reoperation if bilateral surgery is completed or the risk is mainly determined by other factors such as radiation for example, which would most likely only be administered to one breast. We were also unable to identify the specific indication (i.e. cosmesis concern versus true complication) for revisions. In some situations, patients and providers may consider some revisions for cosmetic concerns as anticipated or planned events, which is a limitation of the classification used. The billing codes for the reoperations were most commonly "breast mound revision or correction" "scar revision" or "debridement of skin flap" and due to the lack of distinction between these descriptions, more granular information regarding reoperation indications were not available and therefore not included. Eventual complete failure of PMBR (i.e. complete debridement of a failed reconstruction or removal of breast prosthesis) was

This article is protected by copyright. All rights reserved. 
also not identifiable. Lastly, we included all patients, and then only patients who underwent immediate reconstruction, for our analyses of factors influencing unplanned reoperations. While radiation was identified as a risk factor, these analyses did not evaluate if radiation was an effect modifier and therefore this is a limitation of our study but does provide an opportunity for future evaluation. Overall, these limitations are partially offset by the large scale, long-term and inclusive assessment of PMBR reoperations made possible by these administrative data and none of these factors would have altered our findings. The information from our study provides useful information for surgeons and physicians alike, with an understanding that individual practitioners will experience both more, and less, favorable reoperation rates. In addition, the experience within Ontario, Canada, that we have reported may not be reflective of the practice patterns and patient populations at specific hospitals, certain regions and other time periods for patients undergoing breast reconstruction and subsequent reoperations.

\section{Conclusions}

Our study provides important long-term population-level data regarding factors influencing unplanned reoperations following both implant-based and autologous methods of PMBR. Patients undergoing microsurgical PMBR or postmastectomy radiation may expect to have a higher rate of additional procedures over time following their first PMBR. In addition, once a patient experiences an unplanned reoperation, she should be counseled that her risk of additional reoperations is significantly increased. These results can aid quality improvement initiatives, but

This article is protected by copyright. All rights reserved. 
perhaps more importantly, can be used to inform physician communication of patient expectations regarding the PMBR surgical journey.

\section{Acknowledgements}

Parts of this material are based on data and information compiled and provided by CIHI. However, the analyses, conclusions, opinions and statements expressed herein are those of the author, and not necessarily those of CIHI

The authors also wish to acknowledge that this study is supported by ICES, which is funded by an annual grant from the Ontario Ministry of Health and Long-Term Care (MOHLTC). The opinions, results and conclusions reported in this paper are those of the authors and are independent from the funding sources. No endorsement by ICES or the MOHLTC is intended or should be inferred.

Research grant support:

Canadian Breast Cancer Foundation Ontario Region, Research Project Funding (T.Z. and N.B.) and the Physicians’ Services Inc. Foundation, Health Research Grant (A.R., N.B and T.Z)

Awards/Salary support:

Canadian Breast Cancer Foundation, Ontario Fellowship program - salary support (A.R.)

Career Development Award from the American Society of Clinical Oncology (T.Z)

Abbreviations list

This article is protected by copyright. All rights reserved. 
AG-CP Andersen-Gill counting process

CIHI Canadian Institute for Health Information

DAD Discharge Abstract Database

DBR Delayed breast reconstruction

DIEP Deep inferior epigastric perforator

IBR Immediate breast reconstruction

ICES Institute for Clinical Evaluative Sciences

INST Institution Information System

IPDB Physician Data Base

MOHLTC Ministry of Health and Long-Term Care

NACRS National Ambulatory Care Reporting System

NAC Nipple areolar complex

NSQIP National Surgical Quality Improvement Program

OCR Ontario Cancer Registry

OHIP Ontario Health Insurance Plan

PMBR Post-Mastectomy Breast Reconstruction

This article is protected by copyright. All rights reserved. 
RPDB Registered Persons Database

SEER Surveillance, Epidemiology and End Results program

TRAM Transverse rectus abdominis myocutaneous

\section{References}

1. Birkmeyer JD, Hamby LS, Birkmeyer CM, Decker MV, Karon NM, Dow RW. Is unplanned return to the operating room a useful quality indicator in general surgery? Arch Surg. 2001 Apr;136(4):405-11.

2. Kroon HM, Breslau PJ, Lardenoye JW. Can the incidence of unplanned reoperations be used as an indicator of quality of care in surgery? Am J Med Qual. 2007 May-Jun;22(3):198-202.

3. Farhangkhoee H, Matros E, Disa J. Trends and concepts in post-mastectomy breast reconstruction. J Surg Oncol. 2016 Feb 14. doi: 10.1002/jso.24201.

4. Boughey JC, Hoskin TL, Hartmann LC, Johnson JL, Jacobson SR, Degnim AC, Frost MH. Impact of reconstruction and reoperation on long-term patientreported satisfaction after contralateral prophylactic mastectomy. Ann Surg Oncol. 2015 Feb;22(2):401-8.

5. Jagsi R, Jiang J, Momoh A, et al. Complications after Mastectomy and Immediate Breast Reconstruction for Breast Cancer: A Claims-based Analysis. Ann Surg. 2016 February; 263(2): 219 - 227

6. Fischer JP, Wes AM, Nelson JA et al. Propensity-matched, longitudinal outcomes analysis of complications and cost: comparing abdominal free flaps 
and implant-based breast reconstruction. J Am Coll Surg 2014 Aug;219(2):303-

7. Potter S, Brigic A, Whiting PF et al. Reporting clinical outcomes of breast reconstruction: a systematic review. J Natl Cancer Inst. 2011 Jan 5; 103(1):3146

8. Sanati-Mehrizy P, Massenburg BB, Rozehnal JM,et al. A Comparison of Postoperative Outcomes in Immediate Versus Delayed Reconstruction After Mastectomy. Eplasty. 2015 Sep 30;15:e44. eCollection 2015.

9. Roberts A, Baxter N, Camacho X, Lau C, Zhong T. Once is Rarely Enough: A Population-Based Study of Reoperations after Postmastectomy Breast Reconstruction. Ann Surg Oncol. 2015 Oct;22(10):3302-7.

10. Platt J, Zhong T, Moineddin R et al. Geographic Variation Immediate and Delayed Breast Reconstruction Utilization in Ontario, Canada and Plastic Surgeon Availability: A Population-Based Observational Study. World J Surg. 2015 Aug; 39(8): 1909-21.

11. Cook RJ, Lawless JF. Analysis of repeated events. Stat Methods Med Res. 2022; 11: 141-166.

12. Sutradhar R, Lokku A, Barbera L. Cancer survivorship and opiod prescribing rates: population-based matched cohort study among individuals with and without a history of cancer. Cancer. 2017; 123: 4286-4293.

13. Eriksson M, Anveden L, Celebioglu F, et al. Radiotherapy in implant-based immediate breast reconstruction: risk factors, surgical outcomes, and patient-

This article is protected by copyright. All rights reserved. 
reported outcome measures in a large Swedish multicenter cohort. Breast Cancer Res Treat. 2013 Dec;142(3):591-601.

14. Schaverien MV, Macmillan DR, McCulley SJ. Is immediate autologous breast reconstruction with postoperative radiotherapy good practice?: a systematic review of the literature. J Plast Reconst Aesth Surg 2013;66:1637e51

15. Ricci JA, Epstein S, Momoh AO, Lin SJ, Singhal D, Lee BT. A meta-analysis of implant-based breast reconstruction and timing of adjuvant radiation therapy. J Surg Res. 2017 Oct;218:108-116.

16. Magill LJ, Robertson FP, Jell G, Mosahebi A, Keshtgar M. Determining the outcomes of post-mastectomy radiation therapy delivered to the definitive implant in patients undergoing one- and two-stage implant-based breast reconstruction: A systematic review and meta-analysis. J Plast Reconstr Aesthet Surg. 2017 Oct;70(10):1329-1335.

17. Wilkins EG, Hamill JB, Kim HM, Kim JY, Greco RJ, Qi J, Pusic AL. Complications in Postmastectomy Breast Reconstruction: One-year Outcomes of the Mastectomy Reconstruction Outcomes Consortium (MROC) Study Ann Surg. 2016 Nov 30.

18. Qin Q, Tan Q, Lian B, Mo Q, Huang Z, Wei C. Postoperative outcomes of breast reconstruction after mastectomy: A retrospective study. Medicine (Baltimore). 2018 Feb;97(5):e9766.

19. Bodin F, Dissaux C, Lutz JC, Hendriks S, Fiquet C, Bruant-Rodier C. The DIEP flap breast reconstruction: Starting from scratch in a university hospital. Ann Chir Plast Esthet. 2015 Jun;60(3):171-8.

This article is protected by copyright. All rights reserved. 
20. Damen TH, Morritt AN, Zhong T, Ahmad J, Hofer SO. Improving outcomes in microsurgical breast reconstruction: lessons learnt from 406 consecutive DIEP/TRAM flaps performed by a single surgeon. J Plast Reconstr Aesthet Surg. 2013 Aug;66(8):1032-8.

21. Kamali, P, Paul MA, Ibrahim AMS, et al. National and Regional Differences in 32,248 Postmastectomy Autologous Breast Reconstruction Using the Updated National Inpatient Survey. Annals of Plastic Surgery. 78(6):717-722, Jun 2017

22. Unukovych D, Hernandez Gallego C, Aineskog H, Rodriguez-Lorenzo A, Mani M. Predictors of Reoperations in Deep Inferior Epigastric Perforator Flap Breast Reconstruction. Plast Reconstr Surg Glob Open. 2016 Aug; 4(8): e1016

23. Forster NA, Künzi W, Giovanoli P. The reoperation cascade after breast augmentation with implants: what the patient needs to know. J Plast Reconstr Aesthet Surg. 2013 Mar;66(3):313-22

Table 1. Baseline Characteristics for Individuals with Invasive Breast Cancer Diagnosis

\begin{tabular}{lcccc}
\hline & No & At least 1 & & \\
Characteristi & $\begin{array}{c}\text { unplanned } \\
\text { reoperatio } \\
\text { c }\end{array}$ & unplanned & & P- \\
reoperatio & & $\mathrm{n}^{*}$ & TOTAL & VALU \\
& & & & \\
& $\mathrm{N}=1,482$ & $\mathrm{~N}=1,584$ & $\mathrm{~N}=3,066$ \\
\hline
\end{tabular}

This article is protected by copyright. All rights reserved. 


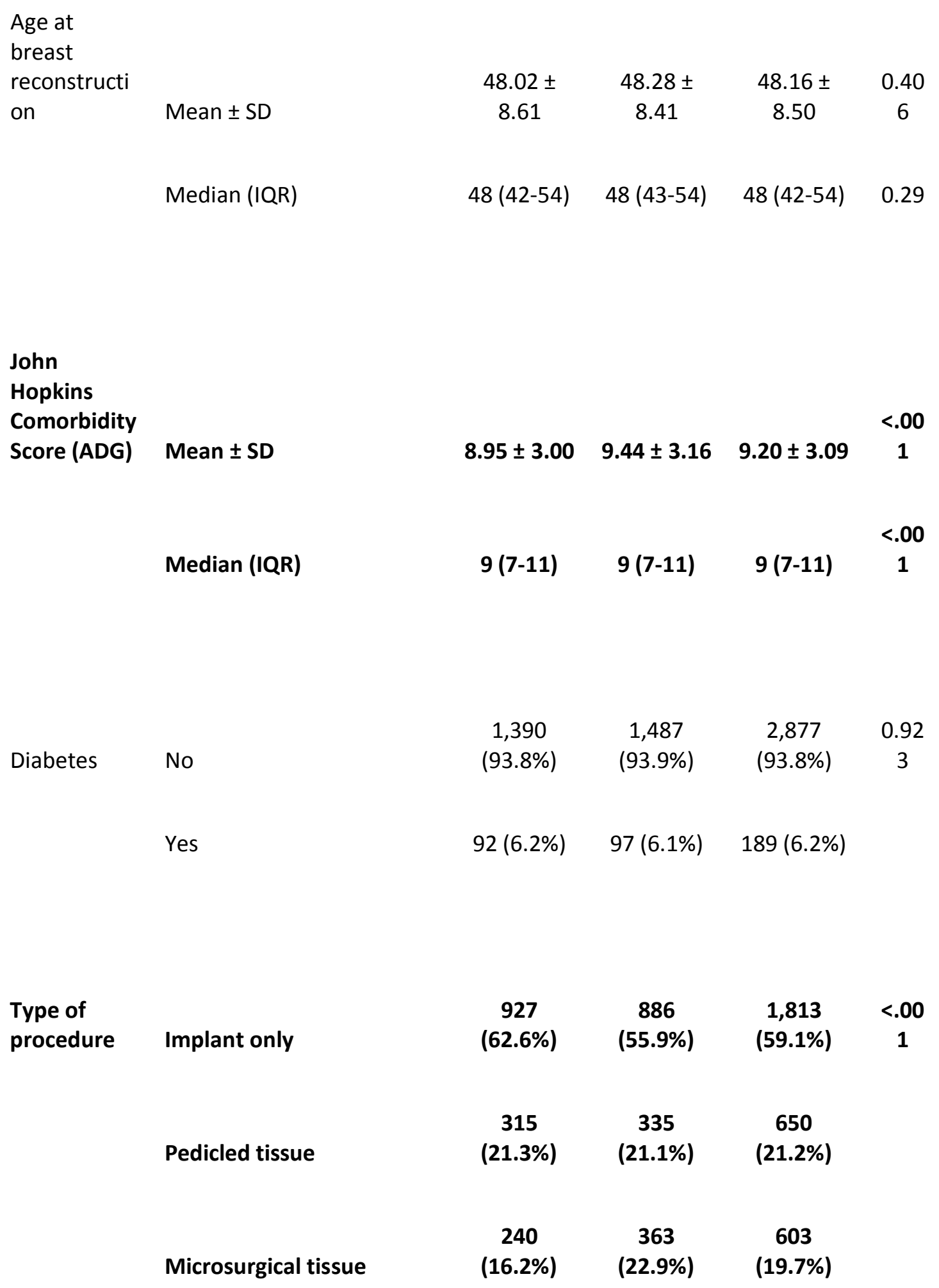

John

Hopkins

Comorbidity

Score (ADG) Mean \pm SD

1

.00

breast

reconstructi

Mean \pm SD

$48.02 \pm$

40

Median (IQR)

$8.95 \pm 3.00 \quad 9.44 \pm 3.16 \quad 9.20 \pm 3.09$

$\begin{array}{llll}1,390 & 1,487 & 2,877 & 0.92\end{array}$

$\begin{array}{llll}(93.8 \%) & (93.9 \%) & (93.8 \%) & 3\end{array}$

$92(6.2 \%) \quad 97(6.1 \%) \quad 189(6.2 \%)$

$\begin{array}{lll}(16.2 \%) & (22.9 \%) & (19.7 \%)\end{array}$

This article is protected by copyright. All rights reserved. 


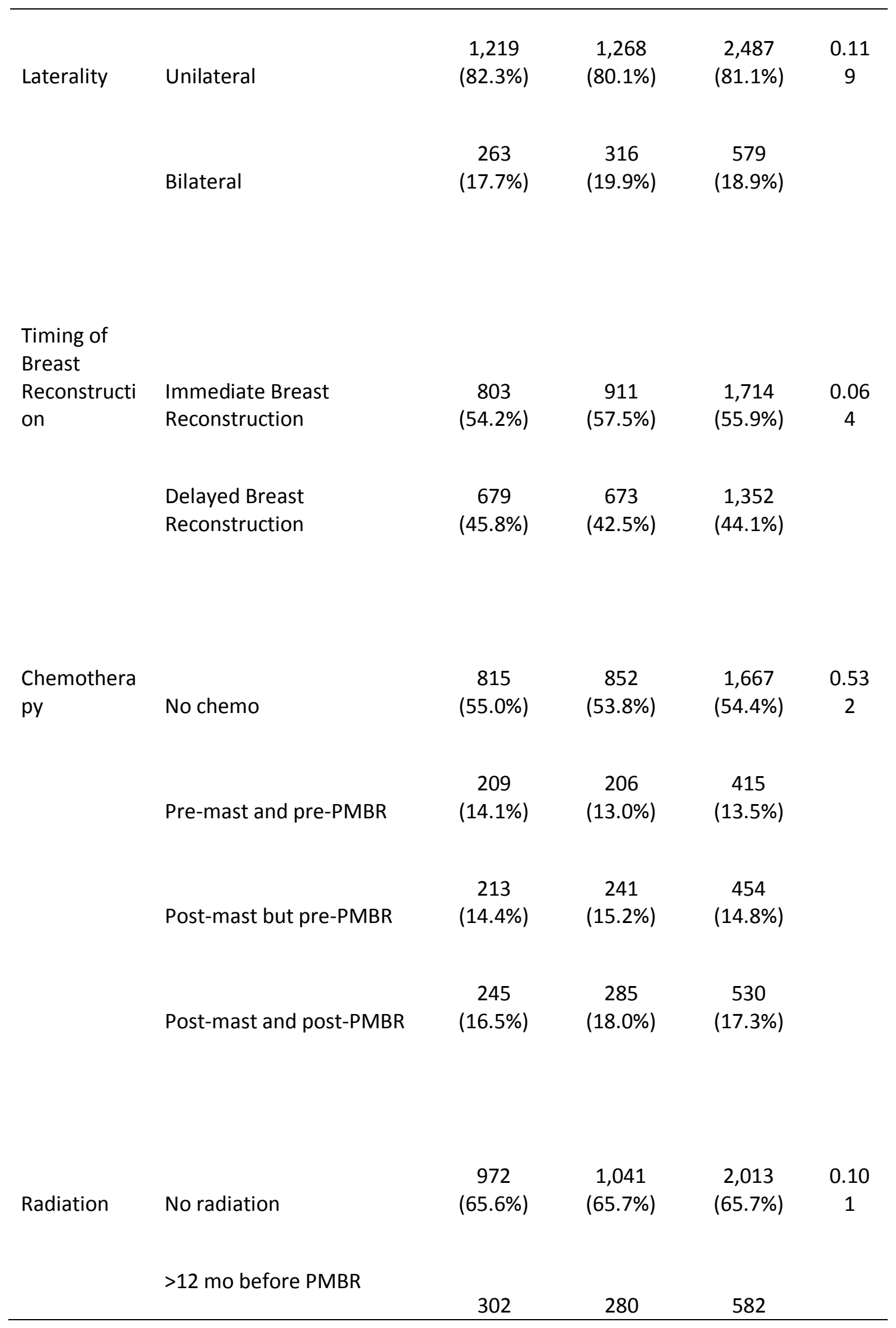

This article is protected by copyright. All rights reserved. 


\begin{tabular}{|c|c|c|c|c|c|}
\hline & & $(20.4 \%)$ & $(17.7 \%)$ & $(19.0 \%)$ & \\
\hline & $<12$ mo before PMBR & $99(6.7 \%)$ & $126(8.0 \%)$ & $225(7.3 \%)$ & \\
\hline & anytime after PMBR & 109 (7.4\%) & 137 (8.6\%) & $246(8.0 \%)$ & \\
\hline $\begin{array}{l}\text { Average } \\
\text { volume of } \\
\text { breast }\end{array}$ & & & & & \\
\hline $\begin{array}{l}\text { reconstructi } \\
\text { ons per year }\end{array}$ & Mean \pm SD & $\begin{array}{c}37.85 \pm \\
32.55\end{array}$ & $\begin{array}{c}31.71 \pm \\
27.83\end{array}$ & $\begin{array}{c}34.68 \pm \\
30.35\end{array}$ & $\begin{array}{c}<.00 \\
1\end{array}$ \\
\hline (physician & & & & & $<.00$ \\
\hline level) & Median (IQR) & $32(11-53)$ & $24(9-48)$ & $28(10-51)$ & 1 \\
\hline \multirow[t]{2}{*}{$\begin{array}{l}\text { Sex of } \\
\text { physician }\end{array}$} & Male & $\begin{array}{c}889 \\
(60.0 \%)\end{array}$ & $\begin{array}{c}936 \\
(59.1 \%)\end{array}$ & $\begin{array}{c}1,825 \\
(59.5 \%)\end{array}$ & $\begin{array}{c}0.61 \\
4\end{array}$ \\
\hline & Female & $\begin{array}{c}593 \\
(40.0 \%)\end{array}$ & $\begin{array}{c}648 \\
(40.9 \%)\end{array}$ & $\begin{array}{c}1,241 \\
(40.5 \%)\end{array}$ & \\
\hline \multirow[t]{3}{*}{$\begin{array}{l}\text { Physician } \\
\text { years in } \\
\text { practice }\end{array}$} & Mean \pm SD & $\begin{array}{c}11.53 \pm \\
7.86\end{array}$ & $\begin{array}{c}10.79 \pm \\
7.27\end{array}$ & $\begin{array}{c}11.15 \pm \\
7.57\end{array}$ & $\begin{array}{c}0.00 \\
7\end{array}$ \\
\hline & & & & & 0.01 \\
\hline & Median (IQR) & $10(4-19)$ & $10(4-17)$ & $10(4-18)$ & 7 \\
\hline
\end{tabular}

This article is protected by copyright. All rights reserved. 


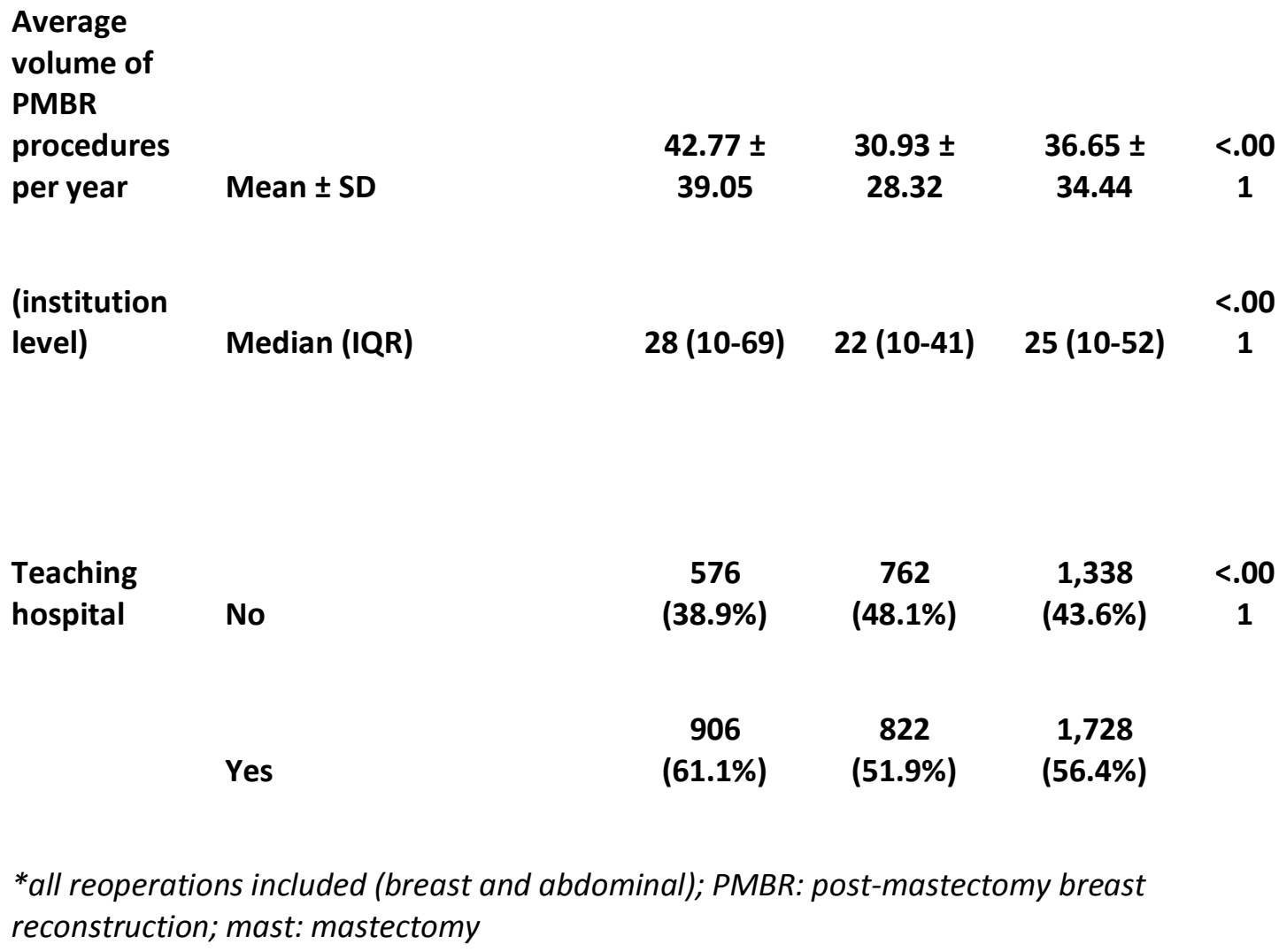

(institution

level) Median (IQR)

$\begin{array}{llll}42.77 \pm & 30.93 \pm & 36.65 \pm & <.00\end{array}$

$\begin{array}{llll}39.05 & 28.32 & 34.44 & 1\end{array}$

Teaching

hospital

No

576

762

(48.1\%)

$1,338<.00$

(38.9\%)

$(43.6 \%)$

1

$\begin{array}{cccc} & 906 & 822 & 1,728 \\ \text { Yes } & (61.1 \%) & (51.9 \%) & (56.4 \%)\end{array}$

*all reoperations included (breast and abdominal); PMBR: post-mastectomy breast reconstruction; mast: mastectomy

Table 2. Factors Influencing Breast Mound Reoperation for Invasive breast cancer patients undergoing Post-mastectomy Reconstruction: multivariate analysis $(\mathrm{N}=3,066)$

\begin{tabular}{|c|c|c|c|c|c|}
\hline Variable & & $\begin{array}{l}\text { Referenc } \\
\text { e }\end{array}$ & $\begin{array}{l}\mathbf{P} \\
\text { value }\end{array}$ & $\begin{array}{l}\text { Hazard } \\
\text { Ratio }\end{array}$ & $\begin{array}{l}95 \% \\
\text { CI }\end{array}$ \\
\hline Timing of procedure & Delayed & $\begin{array}{l}\text { Immediat } \\
\text { e }\end{array}$ & 0.47 & 1.04 & $\begin{array}{c}(0.93- \\
1.16)\end{array}$ \\
\hline $\begin{array}{l}\text { Patient age at PMBR (per } \\
10 \text { years) }\end{array}$ & & & 0.23 & 1.04 & $\begin{array}{l}(0.98- \\
1.10)\end{array}$ \\
\hline Bilateral & Yes & No & 0.09 & 1.10 & $\begin{array}{c}(0.98- \\
1.24)\end{array}$ \\
\hline
\end{tabular}

This article is protected by copyright. All rights reserved. 
Patient Comorbidity score

$\begin{array}{lll}0.02 & 1.02 \quad(1.00- \\ & & 1.03)\end{array}$

Procedure type

Microsurgica Implant

1 tissue

0.00

1.27

(1.12 -

1.45)

Pedicled

tissue

$<.0001$

0.64

$(0.55-$

$0.75)$

Radiation after PMBR

Yes

No

0.00

(1.09-

Chemotherapy after

PMBR

Yes

No

0.36

0.95

(0.86-

PMBR

Physician sex

Female

Male

0.07

0.91

(0.82-

1.01)

Physician years in practice

(per 10 years)

0.46

0.97

(0.90-

Physician average volume of breast reconstructions

per year (per 10 procedure)

$\begin{array}{lll}0.57 & 0.99 & (0.97- \\ & & 1.02)\end{array}$

Teaching Hospital

No

Yes

0.01

1.16

(1.03-

Average volume of PMBR related procedures per year (per 20 procedures)

0.83

1.01

(0.96-

Number of prior unplanned reoperations

$<.0001$

1.25

(1.18-

PMBR: Post-mastectomy breast

reconstruction

This article is protected by copyright. All rights reserved. 


\section{University Library}

\section{- M M N E R VA A gateway to Melbourne's research publications}

Minerva Access is the Institutional Repository of The University of Melbourne

Author/s:

Roberts, A;Baxter, NN;Sutradhar, R;Lau, C;Zhong, T

Title:

Reoperation cascade in postmastectomy breast reconstruction and its associated factors: Results from a long-term population-based study

Date:

2020-09-15

\section{Citation:}

Roberts, A., Baxter, N. N., Sutradhar, R., Lau, C. \& Zhong, T. (2020). Reoperation cascade in postmastectomy breast reconstruction and its associated factors: Results from a long-term population-based study. JOURNAL OF SURGICAL ONCOLOGY, 122 (7), pp.1300-1306. https://doi.org/10.1002/jso.26166.

Persistent Link:

http://hdl.handle.net/11343/276303 